\title{
Evaluation of the efficiency of the various techniques used for screening of HIV in antenatal mothers to facilitate early initiation of treatment
}

\author{
Kola Sujatha, ${ }^{1, *}$, ML. Kavitha ${ }^{2}$ \\ Assistant Professor, Dept. of Microbiology, ${ }^{1}$ RVM Institute of Medical Sciences and Research Center, Laxmakkapally, \\ Telangana, ${ }^{2}$ Gandhi Medical College, Secunderabad, Telangana, India
}

*Corresponding Author:

Email: bhogadi.sujatha@gmail.com

\begin{abstract}
The study has been conducted in pregnant women in the high risk category attending the antenatal O.P at M.N.R Hospital and medical college and Niloufer Hospital for a defined period. The screening tests for HIV used are Coombaids, (Dot Immunoassay), as per NACO guidelines \& Fourth- Generation (double antigen/antibody Sandwich with solid micro wells precoated with Recombinant HIV-1gp41, HIV-1 Group O gp41, HIV-2 gp36, \& amp; Monoclonal Anti p24 Antibodies. The individual sensitivity and specificity were evaluated and compared. The sera of all the women screened by COOMBAIDS were tested negative \& out of all the negative samples one sample was tested positive by 4 th generation ELISA. Hence, this study was carried out to evaluate the sensitivity and specificity of various techniques for Antibody detection and Antigen detection, and to determine the technique most suitable for early diagnosis of HIV infection. ${ }^{4}$
\end{abstract}

Keyword: Antenatal women, Specificity and Sensitivity.

\section{Introduction}

The emergence and pandemic spread of HIV infection, leading to the Acquired Immunodeficiency Syndrome (AIDS), has posed the greatest challenge to public health in modern times prevalence is 0.90 percent among adults (15-49 yrs.), 1.22 percent among pregnant women. ${ }^{1}$ Most of these patients are aged $20-$ 49 years, the sexually active group. ${ }^{2}$ This group represents the most productive members of the society, and those responsible for child-bearing and childcaring. Hence, early detection of HIV is important for reasons of Infection security, prevention, and individual prognosis. Antiretroviral combination therapy started early, during Primary HIV infection, reduces the likelihood of a rapid progression to the AIDS stage. Moreover, the frequency of opportunistic infections later, is reduced, enhancing the quality of life. ${ }^{3}$ Early detection of HIV infection in Antenatal women is even more essential. Hence, this study was carried out to evaluate the sensitivity and specificity of various techniques for Antibody detection and Antigen detection, and to determine the technique most suitable for early diagnosis of HIV infection. ${ }^{4}$

One hundred and seven Antenatal women with high risk-group husbands attending the Outpatient Departments of, MNR Hospital, Sangareddy, and Maternity hospital, Nayapul. The sensitivity and specificity of various techniques prescribed for this group, as per Algorithms from NACO Guidelines were compared to the sensitivity and specificity of FourthGeneration ELISA (for both Ag \& Ab detection), in an attempt to determine the assay most useful in reducing the diagnostic window between HIV Infection and Lab Diagnosis.

\section{Material and Methods}

The present study was conducted in the Department of Microbiology, MNR Medical College, Sangareddy. 107 high risk pregnant women coming for antenatal screening to M.N.R Hospital, Sangareddy and Niloufer Hospital, were collected during the period, April 2017 to May 2018. This was a prospective, hospital-based clinic-microbiological observational study conducted in the Department of Microbiology, MNR Medical College. This study was conducted after approval by the Institutional Research \& Ethics Committee. Informed consent was obtained from the patients for the sample collection and for enrolment in the study.

\section{Inclusion criteria}

1. In this group, One hundred and seven Antenatal women with high risk-group husbands attending the Out Patient Departments of The Dept. of Obstetrics \& Gynecology, MNR Hospital, Sangareddy, and Niloufer Hospital, Hyderabad, were included in the study.

2. Written consent was taken from all the participants. Exclusion criteria:

1. Persons who were not willing to participate in the present study were excluded.

2. Antenatal women, already on Antiretroviral Therapy prior to pregnancy were excluded from the study.

Specimen collection: In this category, blood sample of $2 \mathrm{ml}$ was collected using a sterile $24 \mathrm{G}$ disposable needle $\&$ syringe in plain tubes. The Sera were separated after centrifugation. 


\section{Material and Methods}

All Antenatal women enrolled in the study were counselled and consent was obtained prior to testing .A standard questionnaire regarding demographical profile, socio-economical data, any high risk behavior were collected.

Initially, screening for HIV was performed by Rapid HIV testing method using Combaids kit as per NACO Guidelines, for all pregnant women included in the present study.

1. The sera which were found to be positive for Antibody detection by the Coombaids Rapid test, were subjected to two different anti body detection methods. Pareekshak HIV 1/2 Triline Card Test and AIDSCAN ${ }^{\mathrm{e}}$ HIV-1/2 TRISPOT Test, for confirmation, as per NACO Guidelines.

2. Which were found to be negative for Antibody detection by the Coombaids Rapid test, were taken up for p24 Antigen detection by Fourth-Generation ELISA.

All the test procedures were performed according to the manufacturer's instructions. For the calculation of sensitivity and specificity, sera were considered to be true positive when they were positive by all assays.

Principle and procedure of diagnostic techniques employed

Combaids-RS Advantage-ST. HIV 1+2 Immunodot Test Kit (IVD) Span Diagnostics Ltd.): Dot immunoassay intended for the qualitative detection of IgG/IgM antibodies to the HIV type 1 and / or 2 in human Whole Blood, Serum or Plasma.

\section{Principle}

Dot immunoassay employs the same principle as Enzyme lmmuno Assay (EIA) whereby the immobilised antigen-antibody complex is visualized by means of colour producing (chromogenic) reaction in CombaidsRS Advantage - ST test kit. The coloredend-point is developed by a Colloidal Gold - Protein-A Signal Reagent. Each tooth of the Comb is spotted with a circular spot, one near the tip with an optimally standardized blend of HIV 1 and HIV 2 recombinant antigens and/or synthetic peptides (Test spot), and the other spot, a little above the first spot is spotted with control reagent(Control spot). When incubated with a specimen containing HIV 1 and/or 2 antibodies, these antibodies bind directly to the HIV antigens present in the "Test area" on the tooth of the Comb. The immune complex is directly visualized after incubation with the Colloidal Gold Protein-A Signal Reagent. A positive result is indicated by the presence of pink colored spot/dot in the "Test area" near the tip of the tooth of the Comb where antigens are spotted. The Built in Control is visualized separately in the upper part of the tooth ("Control area"), where Control Reagent has been spotted, serving as the procedural control. A pink coloured spot/ dot will always appear at the "Control area" during the test after application of test sample, detecting presence of human immunoglobulins (IgG), irrespective of the presence or absence of HIV specific antibodies in the specimen.

\section{Interpretation of Results}

The tests were considered positive or reactive if pink coloured spot/dot appeared on both test and Control area, showing either HIV 1 or HIV 2 or both together.

However, intensity of spot /dot was equal to more than 1.0 colour index.

Absence of pink spot / dot in test area indicated a negative/ non reactive result. However in such case the pink spot / dot was present in Control area.

The test were considered as "indeterminate" in case of faint coloured spot/dot in test area having colour intensity between 0.00 and 1.0 colour index. In such case the test was repeated to confirm the results, if the result was still "indeterminant", a fresh sample drawn after 4-8 weeks and retested again. If this test was found positive, it was confirmed with two more Antibody detection tests as per NACO guidelines.

\section{Pareekshak ® HIV 1/2 Triline Card Test (IVD)}

This is an immunochromatographic based assay for the detection of antibodies to HIV-1 \& HIV-2 in Human Serum or Plasma. Since HIV antigens are used for both binding and capturing, this test can detect all classes of HIV antibodies, hence detects early sero conversion.

\section{Principle}

The test employs lateral flow immunochromatographic type assay, and the test device consists of a sample window containing a reagent releasing pad. The reagent releasing pad is held in contact with the porous membrane material. The membrane has four zones. The first zone is mobile and it is at the sample window and it consists of coloured colloidal gold particles sensitized to HIV-antigen. The second and third zone consists of recombinant HIV antigens (recombinant HIV-1gp 41 antigen and C terminal of gp -120 for HIV-1 \& recombinant HIV-2gp36antigen for HIV-2) immobilized on the membrane (Test line). The fourth zone (Control line) consists of control antibody, which is also immobilized on the membrane. If HIV antibody is present in the test sample, it will form a complex with the HIV antigen colloidal gold conjugate and then move on, to be trapped by the test line, causing the formation of red line. The unbound colloidal gold particles continue to move along the strip by capillary action until they come in contact with the control line and are trapped, giving a red line demonstrating the validity of the test.

\section{Interpretation of Result}

Negative Result: The Presence of only one band at ' $\mathrm{C}$ ' 
indicated a negative result.

Positive Result: The presence of a band at ' $\mathrm{C}$ ' and bands at ' 1 ' and / or ' 2 ' within the result window, no matter which band appeared first, indicated a positive result for HIV-1 / I and HIV-2 respectively.

\section{AID SCAN ${ }^{\mathrm{HIV}}$-1 -2 TRI SPOT Test}

This is the $2^{\text {nd }}$ confirmatory test for Antibody detection, as per NACO Guidelines AID SCAN ${ }^{e} \mathrm{HIV}-1$-2 TRI SPOT Test is an immunoassay which employs $r$-proteins for the detection of antibodies to HIV in human serum or plasma. These proteins, which are corresponding to highly antigenic segments of both the structural and non-structural proteins of the HIV constitute the solid phase antigenic absorbent. The use of r-proteins offers the advantage of high degree of specificity and sensitivity due to multiple epitopes. AID SCAN6 HIV1/2 TRI SPOT Test utilizes a unique combination of HIV-1 \& 2 antigens of the virus to selectively detect all subtypes of HIV-1 \& 2 Virus in human serum/plasma with a high degree of sensitivity and specificity.

\section{Principle}

HIV-1 \& HIV-2 antigens (HIV-1 \& HIV-2) and a Control antigen (C) are immobilized on a porous immune filtration membrane. Sample and the reagent pass through the membrane and are absorbed into the underlying absorbent pad.

As the patient's sample drains through the membrane, HIV antibodies if present in serum / plasma, bind to the corresponding immobilized antigens. Unbound serum / plasma proteins are washed off in the subsequent washing step. Addition of the protein-A conjugate results in binding of HIV to give distinct Red Spot near the test region (HIV-1 \& HIV-2). At the control region ("C") a "Built in-Quality Control Spot" has been coated to confirm the proper functioning of the device, reagent and correct procedural application.

\section{Observations and Results}

The present study was carried out in M.N.R Hospital, Sangareddy, in the Department of Microbiology during the period of April 2017 to May 2018. In this Study the Rapid HIV test and $3^{\text {rd }}$ Generation ELISA test for detection of antibody was evaluated and compared with a fourth-generation ELISA detecting both p24 antigen and antibody. 107(42\%) were Antenatal women with high risk-group husbands working as migrated laborers \& drivers, 50(19\%).

The highest number of Antenatal women included in our study were in the 21-25yrs age group (55\%), followed by the $26-30 \mathrm{yrs}$ age group (39\%), the $31-35$ yrs age group (47\%) and lastly the 17-20yrs age group $(2 \%)$.
All the Antenatal women who participated in our study were the categorized on the basis of their Occupation.

$53(50 \%)$ of the One hundred and seven Antenatal women included in our study were house wives, followed by 19(18\%) who were Servants, 19 (18\%) were private job holders, $12(11 \%)$ were labourers, and $4(3 \%)$ were Teachers.

All the 107 Antenatal women chosen for our study, had husbands belonging to different high risk groups: $30(27 \%)$ of the women had husbands who were labourers, followed by 24 (23\%) who were Lorry drivers, 20 (19\%) who were car drivers, 17 (16\%) who were auto drivers, and lastly $16(15 \%)$ who were bus drivers $16(15 \%)$.

The 107 Antenatal women were categorised according to their gestational age: Gestation agewise, the number of Antenatal women in their $4^{\text {th }}$ month of pregnancy were $31(29 \%)$, followed by $22(21 \%)$ in their $5^{\text {th }}$ month , $17(16 \%)$ in their $6^{\text {th }}$ month, $16(15 \%)$ in their $7^{\text {th }}$ month, $15(14 \%)$ in their third month, 4(4\%) in their $8^{\text {th }}$ month, and Lastly, $2(1 \%)$ in their $9^{\text {th }}$ month of pregnancy.

Parity wise, they were categorized as follows: 43 of them $(40 \%)$ were primi gravida, followed by $39(39 \%)$, who were Second gravida, 19(16\%) who were third gravida, $5(5 \%)$ who were fourth gravida, and lastly $1(2 \%)$ who were fifth gravida.

The sera of all 107 Antenatal women enrolled in our study were subjected to HIV screening by Rapid Dot immunoassay called Combaids, as per NACO guidelines, for detection of antibodies to HIV type 1 /and or type 2 . Subsequently, all the 107 sera were subjected to Fourth- Generation ELISA (Erba Sure HIV Gen 4) for detection of

The sera of all 107 Antenatal women tested negative by COMBAIDS Dot Immuno Assay, but One of the 107 sera tested positive by Fourth- Generation ELISA (Erba Sure HIV Gen 4). Both the tests were repeated immediately and were found to yield the same results.

Table 1: Age-Group- Incidence

\begin{tabular}{|l|c|c|}
\hline \multicolumn{1}{|c|}{ Age Group } & No. Tested & Percentage \\
\hline $17-20$ Yrs & 3 & $2 \%$ \\
\hline $21-25$ Yrs & 58 & $55 \%$ \\
\hline $26-30$ Yrs & 41 & $39 \%$ \\
\hline $31-35$ Yrs & 5 & $4 \%$ \\
\hline Total & 257 & $100 \%$ \\
\hline
\end{tabular}




\section{Graph 1}

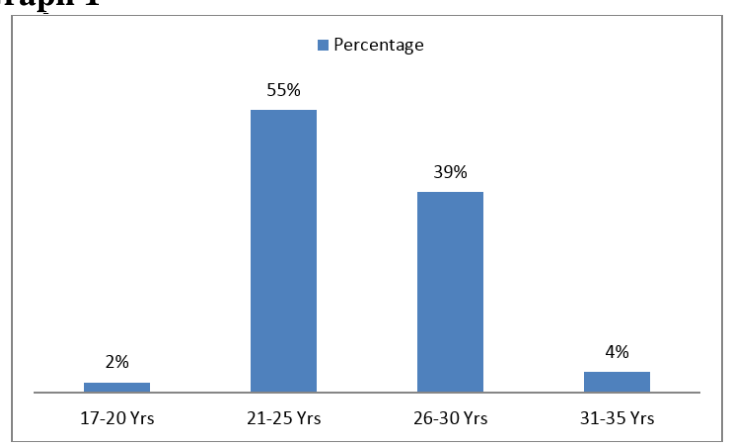

Table 2: Occupation-Incidence

\begin{tabular}{|l|c|c|}
\hline \multicolumn{1}{|c|}{ Occupation } & No. Tested & Percentage \\
\hline House wife & 53 & $50 \%$ \\
\hline Servant & 19 & $18 \%$ \\
\hline Labourer & 12 & $11 \%$ \\
\hline Private Job holder & 19 & $18 \%$ \\
\hline Teacher & 4 & $3 \%$ \\
\hline Total & 107 & $100 \%$ \\
\hline
\end{tabular}

Graph 2

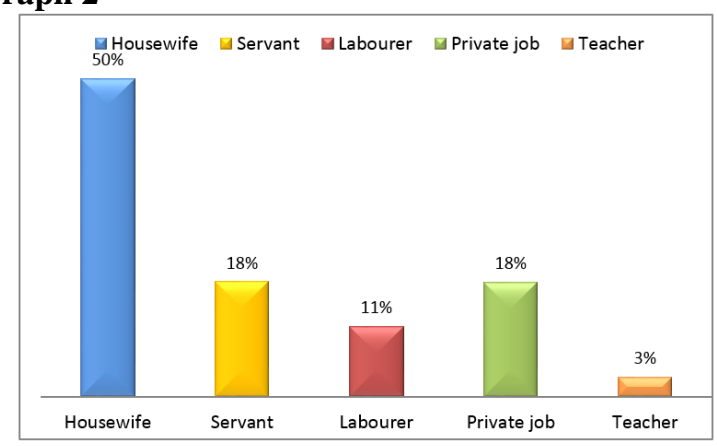

Table 3: High risk-group husbands-incidence

\begin{tabular}{|l|c|c|}
\hline \multicolumn{1}{|c|}{ Occupation } & Number tested & Percentage \\
\hline Labourer & 30 & $27 \%$ \\
\hline Auto driver & 17 & $16 \%$ \\
\hline Bus driver & 16 & $15 \%$ \\
\hline Car driver & 20 & $19 \%$ \\
\hline Lorry driver & 24 & $23 \%$ \\
\hline Total & 107 & $100 \%$ \\
\hline
\end{tabular}

Graph 3: Gestational age- incidence

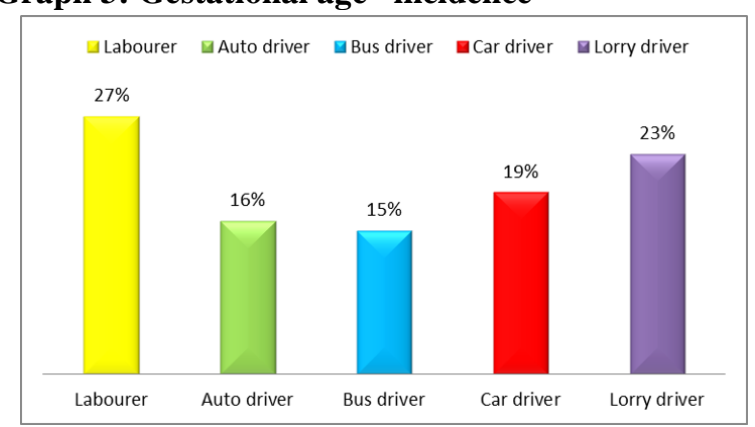

Table 4: Gestational age-Incidence

\begin{tabular}{|l|c|c|}
\hline \multicolumn{1}{|c|}{ Gestational age } & No. tested & Percentage \\
\hline $3^{\text {rd }}$ month & 15 & $14 \%$ \\
\hline $4^{\text {th }}$ month & 31 & $29 \%$ \\
\hline $5^{\text {th }}$ month & 22 & $21 \%$ \\
\hline $6^{\text {th }}$ month & 17 & $16 \%$ \\
\hline $7^{\text {th }}$ month & 16 & $15 \%$ \\
\hline $8^{\text {th }}$ month & 4 & $4 \%$ \\
\hline $9^{\text {th }}$ month & 2 & $1 \%$ \\
\hline Total & 107 & $100 \%$ \\
\hline
\end{tabular}

\section{Graph 4}

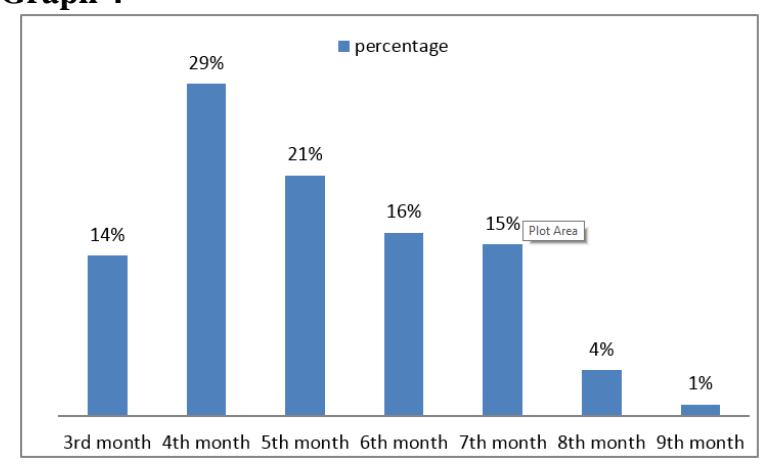

Table 5: Parity-incidence

\begin{tabular}{|c|c|c|}
\hline Parity & No. tested & Percentage \\
\hline G1P0 & 43 & $40 \%$ \\
\hline G2P1 & 39 & $37 \%$ \\
\hline G3p2 & 19 & $16 \%$ \\
\hline G4P3 & 5 & $5 \%$ \\
\hline G5P4 & 1 & $2 \%$ \\
\hline Total & 107 & 100 \\
\hline
\end{tabular}

\section{Graph 5}

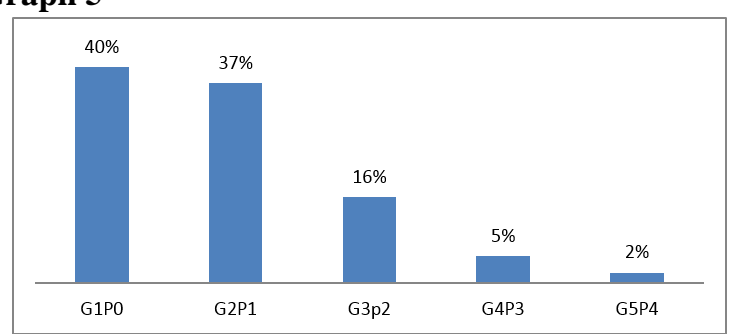

Antibodies to HIV 1/ or 2 as well as for p24 antigen detection. 
Table 6: Test results in antenatal women

\begin{tabular}{|c|c|c|c|c|}
\hline Name of test & No. tested & $\begin{array}{c}\text { No. tested } \\
\text { positive }\end{array}$ & $\begin{array}{c}\text { No. tested } \\
\text { negative }\end{array}$ & $\begin{array}{c}\text { Percentage } \\
\text { Positive }\end{array}$ \\
\hline $\begin{array}{l}\text { Dot Imm. } \\
\text { Assay(COMBAIDS) }\end{array}$ & 107 & Nil & 107 & $0 \%$ \\
\hline $\begin{array}{l}4^{\text {th- Gen ELISA }} \\
\text { (Erba Sure) }\end{array}$ & 107 & 1 & 106 & $0.93 \%$ \\
\hline
\end{tabular}

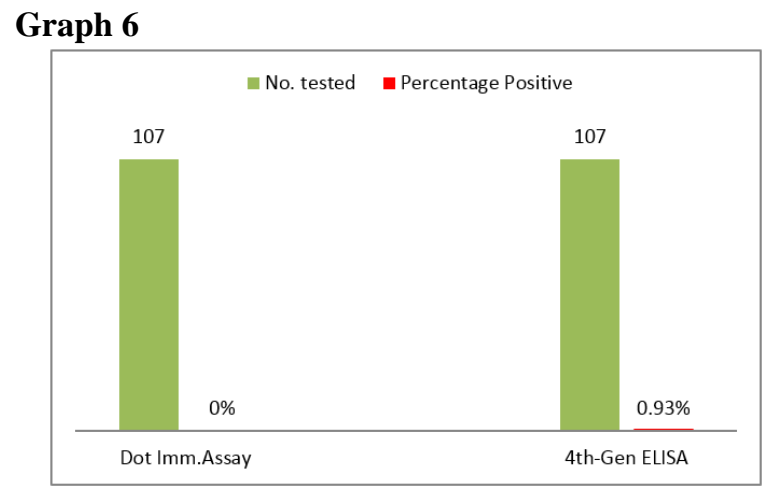

\section{Discussion}

107 pregnant women with high risk-group husbands coming for antenatal screening at M.N.R medical college and hospital, Sangareddy, and Government Maternity Hospital, Nayapul, were collected during the period, April 2017 to May 2018. ${ }^{6}$ Detection of incident HIV infections early in pregnancy increases opportunities for initiating anti-retroviral prophylaxis to prevent mother-to child transmission of HIV. ${ }^{7}$ Estimating the prevalence of HIV in pregnant women provides essential information for an effective implementation of HIV/AIDS control measures and monitoring of HIV spread with in a country.

The objective of this study was to detect early HIV infection, and risk factors for HIV/AIDS among pregnant women attending antenatal clinics. ${ }^{8}$ Majority of the HIV seropositive antenatal attendees did not know their HIV status prior to visiting the clinic for antenatal check-up. The highest number of antenatal women included in our study were in the age group of $21-25$ years (55\%), followed by 26-30yrs (39\%). A study done by Michael Kiptoo* et $\mathrm{al}^{9}$ also reported similar findings. The highest number of Antenatal women in their study were in the age group of $21-$ 25years. (34.8\%). Paras Agarwal et $\mathrm{al}^{10}$ also reported that the highest number of Antenatal women in their study were in the 24-29yrs age group. (43.4\%) which is also similar to our study. Fifty three $(50 \%)$ of the 107 antenatal women who participated in our study were house wives, which was exactly the same as the study done by F1 Buseri et al ${ }^{11}$ $(50 \%)$.

A study of the high- risk categories that the husbands of these antenatal women belonged to, revealed that most of them $(27 \%)$ were migrated labourers, followed by Lorry drivers $19 \% .{ }^{12}$ The role of mobile populations in the spread of HIV has been documented in several countries of the world. The movement of individuals may be linked to permanent or seasonal migration or to occupations such as trading and truck driving. Forty percent reported having had sex with sex workers in neighboring countries. When compared with Arvind Pandey et $\mathrm{al}^{13}$ found skilled labour/drivers were $(60 \%)$, which was higher than our study and Paras Agarwal et al study ${ }^{14}$ found skilled workers $(53.9 \%)$ and followed by un skilled labour $(46 \%)$, which is also higher than our study. It is established that the efficacy of male-to-female transmission of HIV is greater than female-to-male transmission, where infections with other STDs are more prevalent.

The highest number of antenatal women (29\%) enrolled in our study were in their $4^{\text {th }}$ month of gestation, followed by those in the $5^{\text {th }}$ month. Our findings are lower to those of FI Buseri, ESeiyaboh, and ZA Jeremiah et al, ${ }^{11}$ who found that most of their subjects also $(66.8 \%)$, were enrolled in their $5^{\text {th }}$ month of gestational age $(63.8 \%)$.

The majority $40 \%$ of Antenatal women who participated in our study were Primi gravidae, This is in sharp contrast to the study conducted by Buseri, ESeiyaboh et al ${ }^{11}$ who found that multipara constituted the majority (54\%) in their study..

A 25 year-old primi gravida in her $6^{\text {th }}$ month of gestation, a housewife, and not educated. Her husband was an agricultural labourer who worked away from home at Beed, Maharashtra. The detection of p24 Ag by 4th-Generation ELISA indicates that she was in the Acute HIV infection stage, or in the window period, thus enabling early diagnosis and early initiation of treatment. She was promptly started on Anti Retroviral Therapy.

Evidently, the efficiency of $4^{\text {th }}$-Generation Assays is due to their ability to detect p24Ag, enabling early diagnosis of HIV infection.

Other studies where persons who tested negative for Antibodies to HIV-1\&/2, by Rapid tests like COMBAIDS, or by $3^{\text {rd }}$ Generation ELISA, were found to be Positive for p24Ag are given below: 


\begin{tabular}{|l|c|c|c|}
\hline \multicolumn{1}{|c|}{ Author (year) } & $\begin{array}{c}\text { No. of persons } \\
\text { tested }\end{array}$ & $\begin{array}{c}\text { No. tested } \\
\text { +ve for Abs to } \\
\text { HIV 1\&/2 } \\
\text { by Rapid test }\end{array}$ & $\begin{array}{c}\text { No. tested +ve for } \\
\text { p24Ag } \\
\text { by 4 }\end{array}$ \\
\hline T.Sudha et al(2005) & 23609 & 1145 & $6(0.03 \%)$ \\
\hline $\begin{array}{l}\text { Mohammed Mitha et al } \\
(2009)\end{array}$ & 1 & Nil & 1 \\
\hline Present study & 107 & Nil & $1(0.93 \%)$ \\
\hline
\end{tabular}

HIV kits have undergone a considerable range of performance improvements over time with the aim of shortening the window period between infection and the detection of HIV and of ensuring that the various HIV subtypes are detected. ${ }^{17}$ In the late 1990s, fourth generation or combined antigen/antibody ELISA assays were introduced, which incorporate in a single assay, ${ }^{3}$ the advantages of sensitive anti-HIV Antibody detection as well as p24 Antigen detection. The p24 antigen is detectable in blood several days before antiHIV appears. ${ }^{18}$ The $4^{\text {th }}$ generation ELISA assays simultaneously detect antibodies against HIV-1 and 2 and the presence of p24 antigen, and thus shorten the window period to about 14 days.

Currently, Nucleic acid amplification testing (NAT) is considered to be the gold standard for detecting the HIV infected persons during the preseroconversion period as it decreases the window period to around 5 days with ID (individual donation) NAT and 9 days with MP (mini-pool) NAT. ${ }^{19}$ In our study, NAT was not done to confirm the results of $4^{\text {th }}$ generation ELISA due to financial constraints.

The present study also indicates that the performance of 4th Generation assays over $3^{\text {rd }}$ Generation assays, and COMBAIDS, was clinically significant, because of their ability to detect p24 Ag, although it was not statistically significant. ${ }^{20}$

Since p24 is the earliest viral marker and since it may take 2-8 weeks for Antibodies to appear and reach detectable levels, the utility of Fourth-Generation ELISA in detecting HIV infection in the Window period, the seronegative infective stage, and in Acute HIV. ${ }^{21}$

\section{References}

1. Jawetze, melnick \& Adelberg's text book of Medical Microbiology 25th edition

2. Janssen, R., G. A. Satten, S. L. Stramer, B. D. Rawal, T. R. O'Brien, B. J. Weiblen, F. M. Hecht, N. Jack, F. R. Cleghorn, J. O. Kahn, M. A. Chesney, and M. P. Busch.

3. Yerly, S., F. Simon, and L. Perrin. 1999. Early diagnosis of primary HIV infections: using a combined screening test (p24 antigen and anti-HIV antibodies). Swiss J. med. 129:319-Zaaijer, H. L., P. V. Exel-Oehlers, T.

Kraaijeveld, E. Altena, and P. N. Lelie.1992.

4. Weber, B., E. H. M. Fall, A. Berger, and H. W. Doerr. 1998. Reduction of diagnostic window by new fourthgeneration human immunodeficiency virus screening assays. J Clin Microbiol 36:2235-39.

5. Beltrami JF, Franko EA, Tooney KE. Human immunodeficiency virus sero-prevalence trends: five hospitals in South Georgia, 1993 through 1997. Southern Med J 2001;94:421.

6. Brust S, Duttmann H, Feldner J et al. Shortening of the diagnostic window with the new combined HIV p24 antigen and anti-HIV-1/2/O screening test. J Virol Methods 2000;90:153-65.

7. Aubuchon, J. P., J. D. Birkmeyer, and M. P. Busch. 1997. Cost-effectiveness of expanded human immunodeficiency virus-testing protocols for donated blood. Transfusion 45:45-51.

8. Centers for Disease Control and Prevention. Recommendations for human immunodeficiency virus testing services for in-patients and out-patients in acute care hospital settings - recommendations and reports. MMWR 1993;42(RR-02)

9. Paras Agarwal, MM Singh, Suneela Garg, Maternal health-care utilization among women in an urban slum in Delhi Department of Community Medicine, Maulana Azad Medical College, New Delhi, India, 2007

10. CL Townsend*, M Cortina-Borja, CS Peckham and PA Tookey, Trends in management and outcome of pregnancies in HIV-infected women in the UK and Ireland, 1990-2006. Effects of Early, Abrupt Weaning on HIV-free Survival of Children in Zambia(2008)

11. Hugonnet, Frank Mosha, James Todd, Kokugonza Mugeye, Arnoud Klokke, Leonard Ndeki, David Ross, Heiner Grosskurth, Richard Hayes. Incidence of HIV Infection in Stable Sexual Partnerships: A Retrospective Cohort Study of 1802 Couples in Mwanza Region, Tanzania

12. CL Townsend*, M Cortina-Borja, CS Peckham and PA Tookey, Trends in management and outcome of pregnancies in HIV-infected women in the UK and Ireland, 1990-2006Effects of Early, Abrupt Weaning on HIV-free Survival of Children in Zambia(2008)

13. CL Townsend*, M Cortina-Borja, CS Peckham and PA Tookey, Trends in management and outcome of pregnancies in HIV-infected women in the UK and Ireland, 1990-2006Effects of Early, Abrupt Weaning on HIV-free Survival of Children in Zambia(2008)

14. Hugonnet, Frank Mosha, James Todd, Kokugonza Mugeye, Arnoud Klokke, Leonard Ndeki, David Ross; Heiner Grosskurth; Richard Hayes. Incidence of HIV Infection in Stable Sexual Partnerships: A Retrospective Cohort Study of 1802 Couples in Mwanza Region, Tanzania.

15. Hugonnet, Frank Mosha, James Todd, Kokugonza Mugeye, Arnoud Klokke, Leonard Ndeki, David Ross, Heiner Grosskurth, Richard Hayes. Incidence of HIV Infection in Stable Sexual Partnerships: A Retrospective Cohort Study of 1802 Couples in Mwanza Region, Tanzania

16. Weber, B., M. Moshtaghi-Boronjeni, M. Brunner, W. Preiser, M. Breiner,and H. W. Doerr. 1995. Evaluation of 
the reliability of 6 current anti-HIV-1/HIV-2 enzyme immunoassays. J Virol Methods 55:97-104.

17. Yerly, S., F. Simon, and L. Perrin. 1999. Early diagnosis of primary HIV infections: using a combined screening test (p24 antigen and anti-HIV antibodies). Swiss J Med 129:319-Zaaijer, H. L., P. V. Exel-Oehlers, T. Kraaijeveld, E. Altena, and P. N. Lelie.1992.

18. H.S Iqbal, S Solomon, K.G Murugavel, SS Solomon, P Bala Krishnan. Evaluation of two indigenous rapid and two ELISA assays for the diagnosis of HIV infection. India .IJMM 2012

19. Sheetal Malhotra, Neelam Marwaha, and Karan Saluja, Seroprevalence of human immunodeficiency virus in north Indian blood donors using third and fourth generation Enzyme linked immunosorbent assay.

20. Garg S, Mathur DR, Garg DK. Comparision of seropositivity of HIV, HBV, HCV, and syphilis in replacement and voluntary blood donors in Western India. Indian J Pathol/Microbiol 2001;44(4):409-12.

21. Patel Piyusha, Patel Sangeetap, Shahjigeshv, Ozaharenv. Frequency and distribution of blood groups in blood donorsin Western Ahmedabad- a hospital based study 9(2010).

22. Srikrishn A, Sitalaxmi S, Domodhar P. How safe are our safe blood donors. Ind J Pathol Microbial 1999; 42:41116. 